
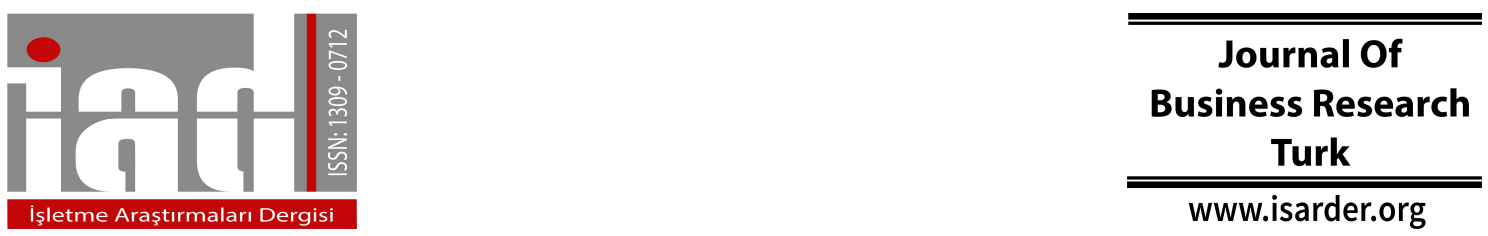

\title{
Structure And Behavior in System Dynamics: A Case Study in Logistic
}

\author{
ArZu EREN ŞENARAS \\ Uludağ University \\ Faculty of Economics and Administrative Sciences \\ Bursa, Turkey \\ orcid.org/0000-0002-3862-4551 \\ arzueren@uludag.edu.tr
}

\begin{abstract}
System dynamics approach is a method used to understand how the system changes over time. The elements and variables that constitute a system that changes in time are expressed as the system behavior. The aim is to understand the basic behavior system of the variables, to discover the factors that cause this mode of behavior and to improve the system behavior. Thus, it could be argued that system dynamics is a method to explain how the systems change with time. The most basic forms of behavior are exponential growth, goal seeking and oscillation. In this study a logistic system was modeled using Vensim Package Program. This model includes two stocks and three flows. Developed system dynamic model provides to analyze the values of product stock, order in transit and received order for 100 weeks.

Keywords: System Dynamics, Exponential Growth, Goal Seeking And Oscillation. Logistic System.

\section{Introduction}

System approach has become a widely used concept. It explains systems based thinking, observation of the systems and its definition. To understand system behavior, dynamic systems simulation analyses are required. System approach includes simulation games related to management problems. These games demonstrate the existence of complexity clearly. While management games focus on decision making, system dynamics reflects the design of policies to guide decisions (Forrester, 2007: 355; Senge, 1990).

System approach is based on three basic principles; integrated approach, interdisciplinary approach and scientific approach. Integrated approach is based on the Aristotelian principle that "the whole is greater than the sum of its parts," and considers the system as a whole that is formed by interactive parts and interacts with the environment. All parts have a functional meaning only when considered as a whole. The problems contained in the system could not be isolated from each other and a solution of one affects the other or could cause further problems. While all sciences were included in philosophy, there were interdisciplinary personalities. Today, as a result of division of labor - specialization, as well as information boom, it became impossible for individuals to have detailed knowledge on different branches of science (disciplines).
\end{abstract}


Thus, today, teamwork replaced interdisciplinary individuals. Interdisciplinary approach is the effort of a team of experts from different scientific fields to resolve problems and make decisions using different perspectives. Scientific approach could be expressed as utilizing adequate scientific methods that are developed based on experimentation, observation and rational proofs in problem solving process as necessary and sufficiently (Sezen, 2007: 6).

The system could be defined as the set of interrelated elements within predetermined limits (Sezen, 2009: 297). System approach is a conceptual framework and enables the observation of the whole system clearly and it makes us see how to change these effectively (Senge, 1994: 10).

As the systems got complicated, inter-system interactions have increased. Thus, the problems that emerge within the system and the system status continuously interact. The models that would be used to examine and assess these systems, which include novel concepts and change continuously, should be designed to

scrutinize the system as a whole of the related processes,

enable the system to monitor the system behavior and changes in that behavior,

$>$ reflect the phenomena that change within the system and conditions that trigger these phenomena,

to provide flexibility in redesign of the system (Erkut, 1995).

The conventional analytical approach implemented to estimate the behavior of a system or to explain the underlying problem concentrates all our attention on the immediate state of the system. In reality, however, events do not work in this way. Events do not determine the system behavior, but they occur as a consequence of the system behavior. If we are to examine how behavior occurs, then it is necessary to determine the system structure that the interactions between the elements of the system create. As it could be observed, the main factor in this approach is to be able to see and understand the whole created by the interactions between the elements of the system. Briefly, we need to make sure that interdependence is fundamental in our approaches rather than linear causality, so that we could better understand the problems we face today. According to Peter Senge, the properties of a system could not be defined by examining the isolated functions of the parts forming the system. Primarily, the behavior of a system is not about the function of each part, but it is about how each piece interacts with the others (Ayanoğlu and Gökçe, 2007).

The systems approach could be expressed as a collection of methods, tools, and principles that examine the relationships between the forces that form organizational decisions and behavior and perceive the forces forming the systems as a part of a common function. The idea underlying systems approach is that all system behavior follow certain common principles. As a new paradigm and method of analysis, systems approach aims to enable us to use our thinking methodology on how to improve organizational operations further more efficiently. Thus, the two keywords System and Thinking together are used to refer to Systems Thinking as a discipline. If a definition is needed for System Thinking / System Dynamics, it could be defined as scientific and artistic activity that attempts to draw reliable conclusions about the behavior of the 
system by continuously developing an in depth understanding of the system's infrastructure (Ayanoğlu and Gökçe, 2007).

System Thinking and System Dynamics provide computer technology and conceptual and numerical modeling techniques that could help explain the dynamics and forces underlying the complexity and change in business, politics, socio-economic and environmental systems. System dynamics, policy analysis and design are used for learning and decision making (Abdelbari et al., 2015; Maani and Cavana, 2007).

System dynamics approach was developed by Jay Forrester from MIT during 1950 's to analyze especially the complex behavior in administration with computer simulation in social sciences. System dynamics is a form of systems approach as a methodology to understand the dynamic behavior of complex systems. The basis of system dynamics is to understand how system structures cause system behavior and system events (Sezen, 2009: 298).

Jay Forrester initially constructed his first dynamic model upon his meeting with the management of General Electric corporation. Big fluctuations in production, inventory, labor force and profitability were compelling GE management. Despite hard efforts of the management, these fluctuations were mostly associated with external factors. Especially, the fluctuations in the business were related to received orders. Forrester interacted with the management to observe the system operations in other departments. In the first model he developed, he observed that simulations were necessary since the system could not be monitored analytically. He demonstrated that the corporation could experience serious fluctuations due to management policies even when the demand is considered constant with the weekly simulation he ran. Later on, he designed the computer simulation for the same problem. In his later studies, Forrester demonstrated how the feedback control theory could be adapted for complex administration and human systems. He published his initial findings in an article in Harvard Business Review. Later on, he developed this study to write his famous work "Industrial Dynamics" (Lane and Sterman, 2011; Ramage and Shipp, 2009: 100-101).

The concept of dynamics indicates change over time. If something is dynamic, it changes constantly. Therefore, a dynamic system is a system in which there are interactions that promote change over time. System dynamics approach is a method used to understand how the system changes over time. The elements and variables that constitute a system that changes in time are expressed as the system behavior. The aim is to understand the basic behavior system of the variables, to discover the factors that cause this mode of behavior and to improve the system behavior. Thus, it could be argued that system dynamics is a method to explain how the systems change with time. In dynamic systems, variables influence each other simultaneously (Barlas, 2005; Ayanoğlu and Gökçe, 2007).

Dynamic complexity arises from connections and disconnections that link social and business systems. When a change occurs in one part of the system, it causes change in another part later (sooner or later). These effects could not always be observed clearly, usually they are beyond expectations (Morecroft, 2015: 21).

Dynamic complexity arises due to the following systems characteristics (Sterman, 2000): 


\section{A. Eren Şenaras 9/4 (2017) 321-340}

Dynamics: Systems constantly change. Even an apparent constant would change over a long time period.

$\checkmark$ Close Relationship: The components of the system have a strong interaction.

$\checkmark$ Management by feedback: Actions return back to themselves. Decisions cause a change and trigger other system components to take action.

$\checkmark$ Nonlinearity: Systems are mostly nonlinear, i.e. the effects are not proportional to their outcomes in general.

$\checkmark$ Historical dependence: Many actions have no return. An action taken will cause irreversible effects as a result of several feedbacks.

$\checkmark$ Self-organization: The dynamics of a system arises from its own internal structure.

$\checkmark$ Adaptability: Rules and abilities change over time. They allow selection and multiplication as they develop over time.

$\checkmark$ Contradiction to intuition: Causes and effects are different from each other in the temporal and spatial contexts. Individuals search for the reasons of events in the periphery of the events they are trying to explain.

$\checkmark$ Resistance to Politics: The complexity of the system that we work on could reduce our ability to understand the system. After all, many obvious solutions fail and even worsen the situation.

$\checkmark$ Determination of Reconciliation: Time delay feedbacks provide different responses in the short and long term. Often a good response occurs before the bad behavior (response).

System dynamics is designed to model, analyze and improve socio-economic and administrative systems using a feedback perspective. Dynamic structured administrative problems are modeled by mathematical equations and using computer software. Dynamic constructions of model variables are obtained using computer simulations (Forrester 1962; Ford 1999; Sterman 2000).

\section{Behavior Patterns}

The behavior of a system originates in the structure of that system. This structure includes feedback loops, accumulations and flows, nonlinear behavior created by the interaction of the physical and institutional structures of the system (Sterman, 2000: 107).

The most basic forms of behavior are exponential growth, goal seeking and oscillation. Each is constructed with a simple feedback structure: growth is created by positive feedback, goal seeking by negative feedback, and oscillation by negative feedback with a delay in the loop. Other forms of general behavior are formed by nonlinear interactions of basic feedback structures (Sterman, 2000: 107). Figure 1 displays the most basic behavior patterns. 


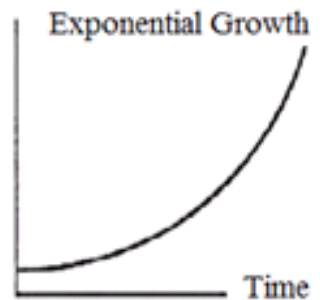

Oscillation

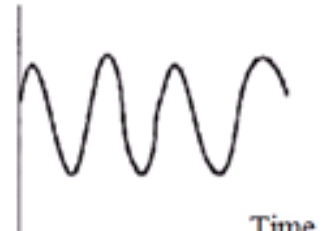

Time

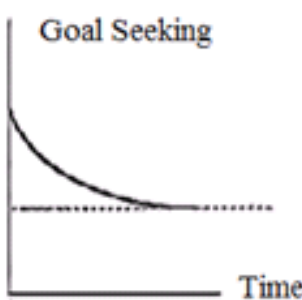

S-Shaped Growth with Overshoot

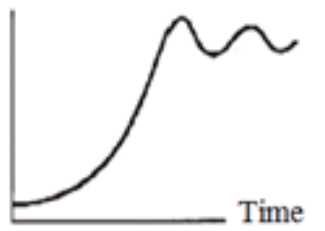

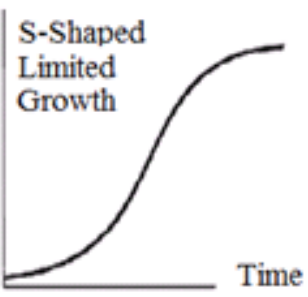

Overshoot and Collapse

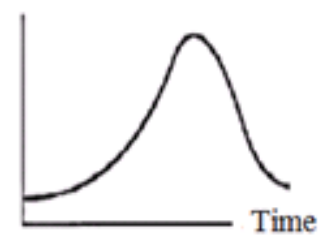

Figure 1: General Dynamic System Behavior Types

\subsection{Exponential Growth}

Exponential growth is born from positive (self-reinforcing) feedback. The larger the quantity, the larger the net increase, the faster the increase in quantity. Compound interest and population growth could be given as examples (Sterman, 2000: 108).

Positive feedback should be reinforced if growth is desired. When it is not desired, positive feedback should be weakened, that is, the growth should be slowed down. Another option would be to include a negative feedback loop in the system or to reinforce an existing negative feedback loop (Erkut, 1983: 62). Figure 2 displays the exponential growth behavior.

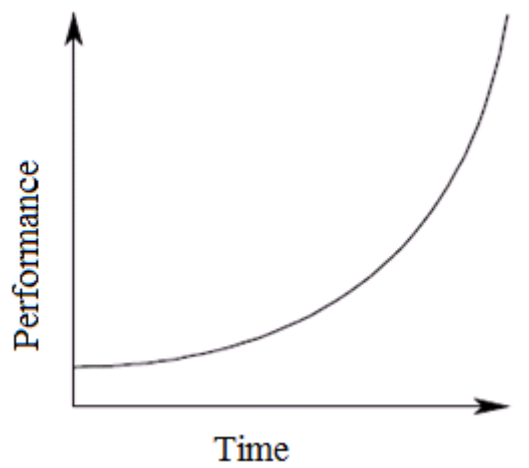

Figure 2: Exponential Growth Behavior

The flow is influenced by the amount of the stock. Stock-dependent feedback determines the flow rate for the next period. In this context, flow is a function of stocks. This structure is shown in Figure 3. 


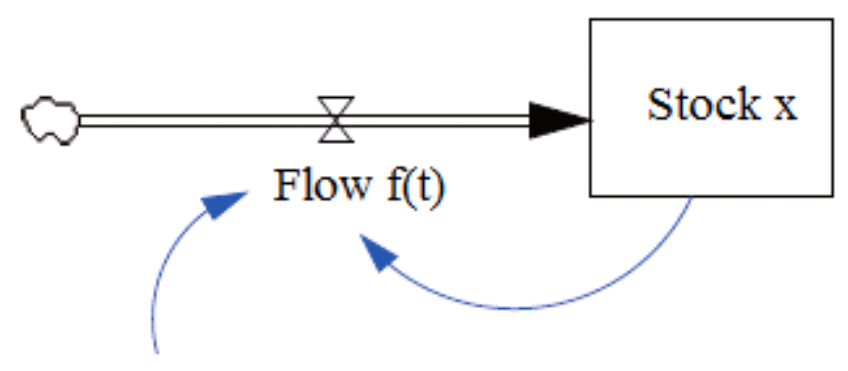

a

Figure 3: Stock-dependent Feedback Structure

In continuous flow, as we have already mentioned above, the differential equation is written as follows:

$$
\frac{d x}{d t}=f(x)
$$

The simplest stock-dependent feedback structure looks like this:

$$
f(x)=a x
$$

The continuous flow here is shown as an autonomous differential equation:

$$
\frac{d x}{d t}=a x
$$

The following result is obtained:

$$
x(t)=x(0) e^{a t} \text { burada } \mathrm{e}=2,718281828 \ldots \ldots \ldots . . .
$$

It should be seen here that $\mathrm{x}(0)$ cannot be 0 (Yamaguchi, 2013: 36).

Let us explain exponential growth behavior by example of interest earnings. The exponential growth behavior in the sample of savings interest revenues in Figure 4 could clearly be observed. Increasing interest income leads to an increase in earnings, which in turn increases interest income. Because, interest income is directly proportional to earnings.

\section{The Algorithm:}

Step 1: Run

Step 2: Get Earnings, Interest, Interest Rate

Step 3: Interest Rate $=0.05$

Step 4: Earnings $=100$

Step 5: Interest= Interest Rate * Earnings

Step 6: Earnings $=$ Earnings + Interest

Step 7: Time $\leq 40 \Rightarrow$ Go to Step 1

Step 8: Time $=40 \Rightarrow$ Halt
a. Stock and Flow Diagram
(1) FINAL TIME $=40$
(2) INITIAL TIME $=0$
(3) INTEREST $=$ INTEREST RATE * SAVING
(4) INTEREST RATE $=0.05$
(5) SAVEPER=TIME STEP
(6) $S A V I N G=I N T E G(I N T E R E S T, 100)$ 
(7) TIME STEP $=0.0625$

\section{b. Feedback Equations}

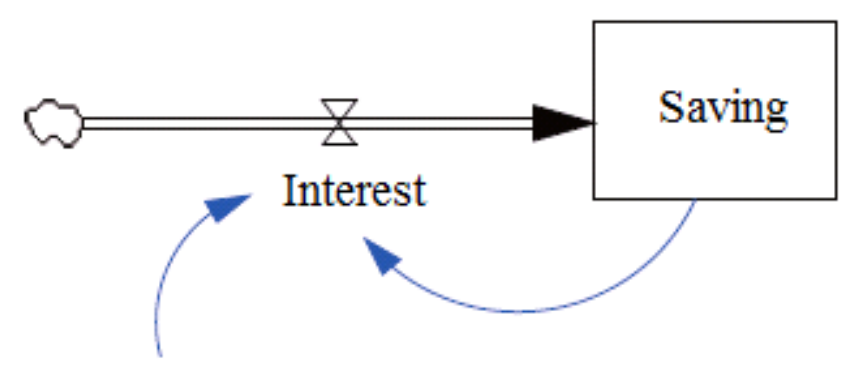

Interest Rate

Figure 4: Exponential Growth Example

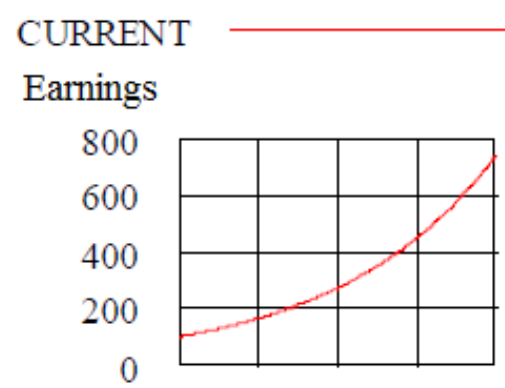

Interest

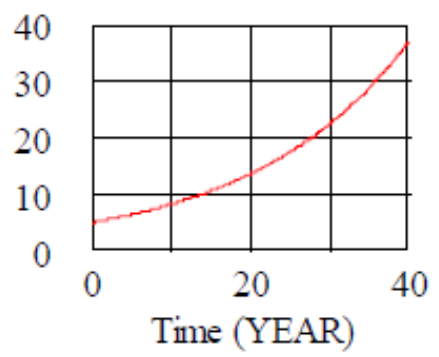

c. For Forty Periods
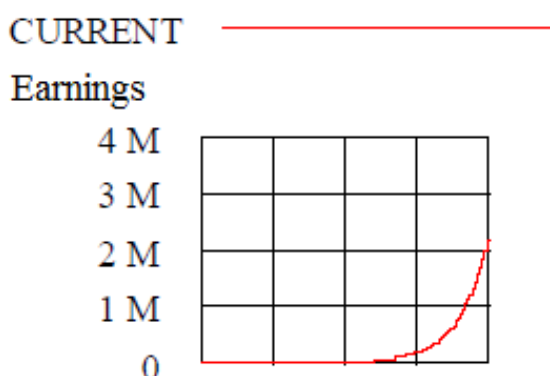

Interest

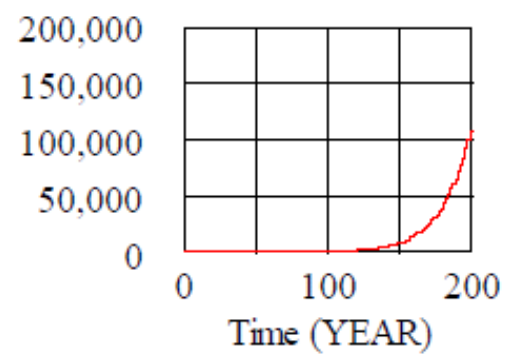

d. For Two-Hundred Periods

Figure 5: Exponential Growth Behavior (Resource: Kirkwood, 1998: 31)

\subsection{Goal Seeking}

If the system only contains exponential growth or only demonstrates positive feedback behavior, it might collapse after a certain period of time. The system needs to find a common objective or a goal. In other words, the system must be stabilized to achieve its goal. The system needs another feedback to self-stabilize. Thus, when $\mathrm{x}(\mathrm{t})$ derives from the $\mathrm{x} *$ equilibrium state, the feedback attempts to bring $\mathrm{x}(\mathrm{t})$ back to equilibrium. Thanks to this characteristics, $x(t)$ shows stable structure in equilibrium. In economics, this is called Global Stasis. Free market economy should provide price stability in order to avoid unstable price fluctuations (Yamaguchi, 2013: 38). Goal seeking behavior is presented in Figure 6. 


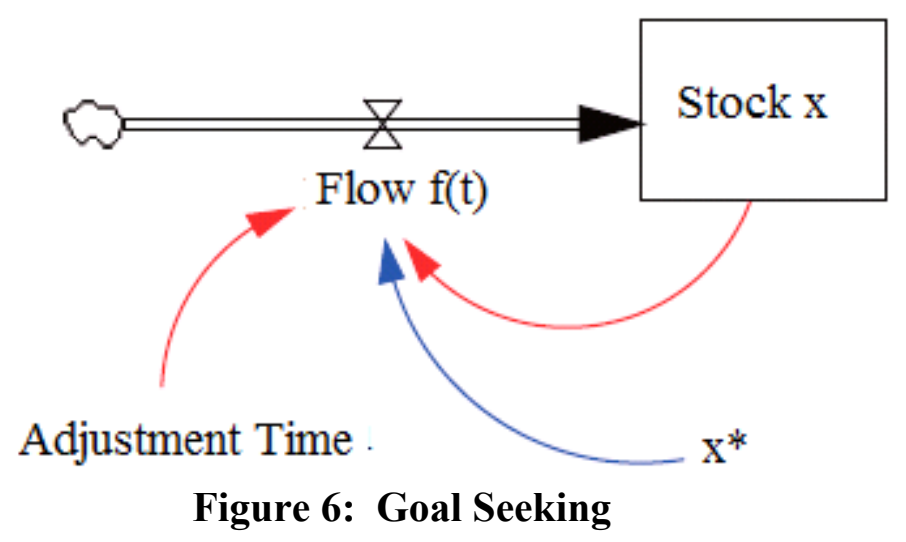

Structural stability is achieved as follows:

If there is an increase in the flow, there is a decrease in the stocks. This in turn reduces the flow. This relationship of structure of stability is called balancing or negative feedback. The balancing behavior is provided by the following flow:

$$
f(x)=\frac{x^{*}-x(t)}{D Z}
$$

$\mathrm{DZ}$ is the correction time of the difference between $\mathrm{x}^{*}$ and $\mathrm{x}$. The differential equation could be analytically solved as follows:

$$
\frac{d\left(x(t)-x^{*}\right)}{x(t)-x^{*}}=-\frac{d t}{D Z}
$$

If the integral of both sides is taken.

$$
\ln \left(x(t)-x^{*}\right)=-\frac{t}{D Z}+C
$$

Here $\ln$ denotes the natural logarithm. If it is rewritten,

$$
\mathrm{x}(\mathrm{t})-\mathrm{x}^{*}=\mathrm{e}^{-\frac{\mathrm{t}}{\mathrm{DZ}}} \mathrm{e}^{\mathrm{C}}
$$

At the beginning of time, when

$$
e^{C}=x(0)-x^{*} \mathrm{t}=0 \text { iken }
$$

Thus, stock amount at time $\mathrm{t}$ is obtained as follows (Yamaguchi, 2013: 38):

$$
x(t)=x^{*}-\left(x^{*}-x(0)\right) e^{-\frac{t}{D Z}}
$$

Goal seeking behavior is shown in Figure 7. 


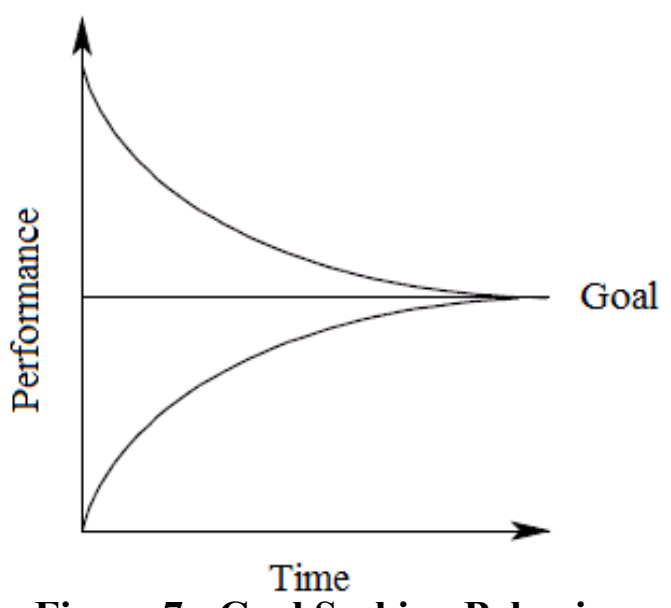

Figure 7: Goal Seeking Behavior

In Figure 8, average sales is given as an example for goal seeking behavior. The effect of increases and decreases in instantaneous sales on average sales could be observed in the graphs.

\section{The Algorithm:}

Step 1: Run

Step 2: Get Average Sales, Change in Average Sales, Instantaneous Sales, Average Time

Step 3: Average time $=2$

Step 4: Average Sales $=100$

Step 5: Instantaneous Sales $=100$

Step 5: Change in Average Sales $=($ Instantaneous Sales - Average Sales $) /$ Average time

Step 6: If time $\geq 10 \Rightarrow$ Instantaneous Sales $=120$

Step 7: Time $\leq 20 \Rightarrow$ Go to Step 1

Step 8: Time $=20 \Rightarrow$ Halt

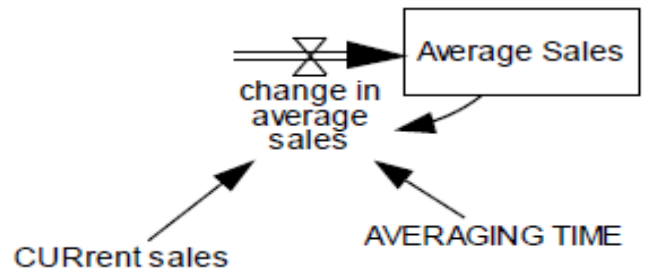

a. Stock and flow diagram

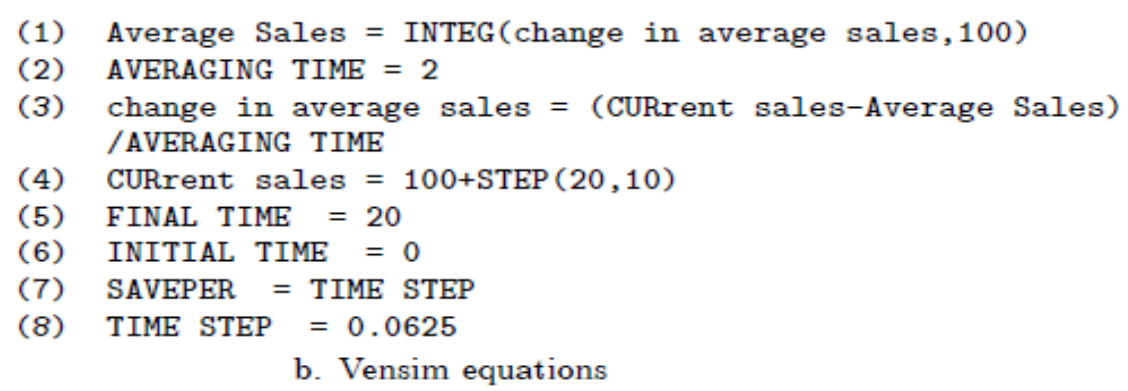

Figure 8: Goal Seeking Example (Resource: Kirkwood, 1998: 33) 


\subsection{Oscillation}

Oscillation is the third type of basic behavior observed in dynamic systems. Similar to the goal seeking behavior, negative feedback cycles are responsible for the oscillation behavior. Corrective actions are taken to compensate for the incompatibility in the system by comparing the state of the system and the objective of the system. In an oscillatory system, the state of the system always exceeds the state of equilibrium, and then the opposite occurs and it goes below the equilibrium state, and the oscillation continues. Overshoot occurs with a noticeable time delay in the negative feedback. Time delay causes corrective actions to continue after the system has reached equilibrium. As a result, the system is over-corrected, triggering an opposite corrective action (Sterman, 2000: 114). There must be at least two stocks present for an oscillation to occur in the process. The degree of oscillation is affected by delays in the system (Kirkwood, 1998: 38). A simple example could be given for two stock systems as follows (Yamaguchi, 2013: 46). The oscillation model is presented in Figure 9.

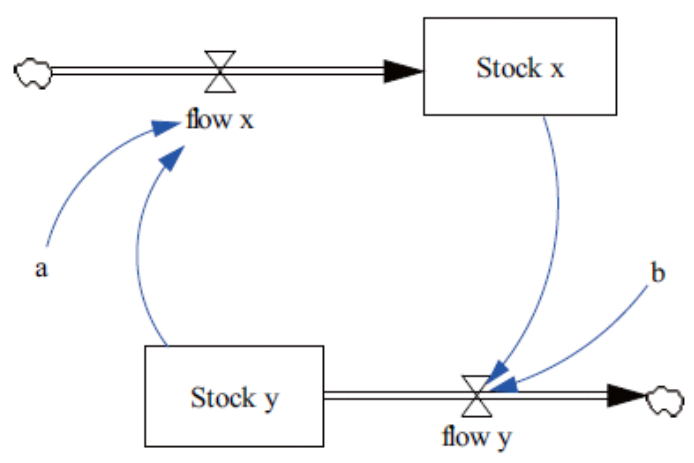

Figure 9: An Oscillation Model (Resource: Yamaguchi, 2013)

$$
\begin{aligned}
& \frac{d x}{d t}=a y, x(0)=1, a=1 \\
& \frac{d y}{d t}=-b x, \quad y(0)=1, b=1
\end{aligned}
$$

There are several oscillation types. Among these, damped oscillations, limit cycles oscillations and chaos oscillations could be specified as the main oscillation types. Each variable is determined by a specific feedback structure, and the parameter groups determine the power of the loops and the lengths of the delays, but the negative feedback loops are common to all (Sterman, 2000: 114).

Figure 10 could be given as an example of an oscillation behavior in a business. When the figure is examined, it could be observed that delays in the information links as well as delay in perception that occurs as a result of measurement and reporting or decision making delays, and delays in the start of corrective actions and in the occurrence of their effects were effective in formation of oscillation behavior. 

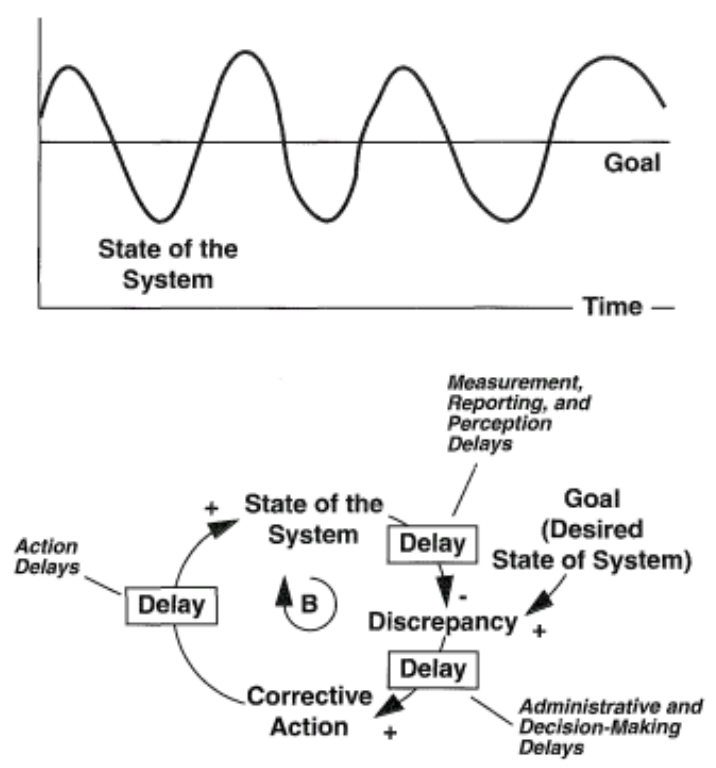

Figure 10: Oscillation Structure and Behavior (Resource: Sterman, 2000: 114)

Figure 11 demonstrates an example of oscillation where a graph of retailer stocks and accepted products could be analyzed.

(01) DESIRED INVENTORY $=200$

(02) factory production $=$ retailer orders

(03) FINAL TIME $=50$

(04) In Transit = INTEG(factory production-orders received, 300)

(05) INITIAL TIME $=0$

(06) product received $=$ DELAY FIXED(factory production,

SHIPPING DELAY, factory production)

(07) Retail Inventory $=$ INTEG(product received-retail sales, 200)

(08) RETail sales $=100+\operatorname{STEP}(20,5)$

(09) retailer orders $=$ retail sales $+($ DESIRED INVENTORY

- Retail Inventory) / TIME TO ADJUST INVENTORY

(10) SAVEPER = TIME STEP

(11) SHIPPING DELAY $=3$

(12) TIME STEP $=0.0625$

(13) TIME TO ADJUST INVENTORY $=2$ 


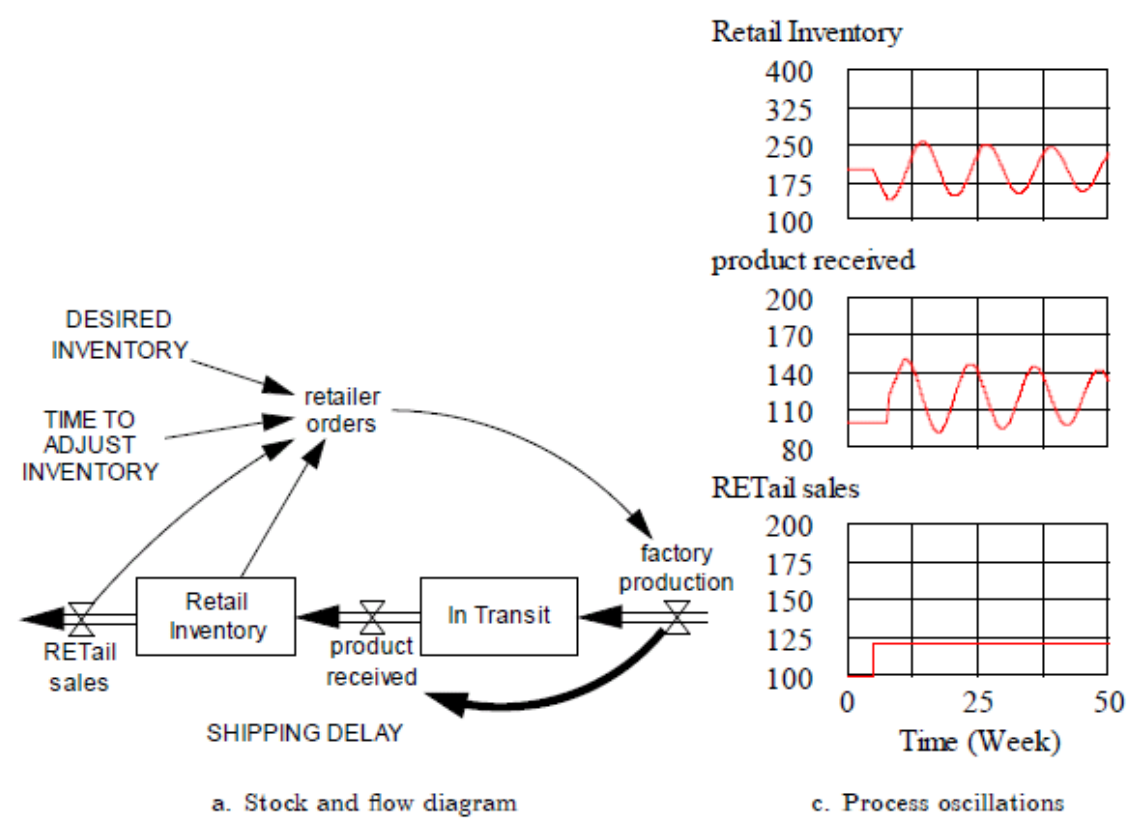

Figure 11: Oscillation Example (Resource: Kirkwood, 1998: 39)

\subsection{S-Shaped Limited Growth}

No actual amount could grow (or decrease) forever; one or more limitations would certainly stop the growth (or the decrease). One of the frequently observed dynamic system behaviors is S-Shaped Limited Growth. At first, the growth behavior is exponential, then gradually the amount of increase decreases to reach the system equilibrium level. As a result, the system looks like an extended S (Sterman, 2000: 118). Examples are the spread of diseases and growth in a population with limited resources (Glick, 2001: 5).

If inflow is greater than outflow in first degree linear models, the system continues to grow in S-shaped limited growth. Population explosion is a good example of this phenomenon. To stabilize the system, the exponential growth ax $(t)$ needs to be slowed down by another balancing feedback. Especially, when $\mathrm{x}(t)$ grows and approaches the limit value $\mathrm{x}^{*}$, the correction factor is activated. This feedback mechanism stabilizes the system. Accordingly, the flow could be expressed as:

$$
f(x)=a x(t) b(t), \text { burada } b(t)=\frac{x^{*}-x(t)}{x^{*}}
$$

As is observed, as $0 \leq \mathrm{b}(t) \leq 1$, and $\mathrm{x}(\mathrm{t})$ approaches $\mathrm{x}^{*}, \mathrm{~b}(t)$ approaches zero. Exponential growth and goal seeking feedback are combined as shown in Figure 12 (Yamaguchi, 2013: 40). 


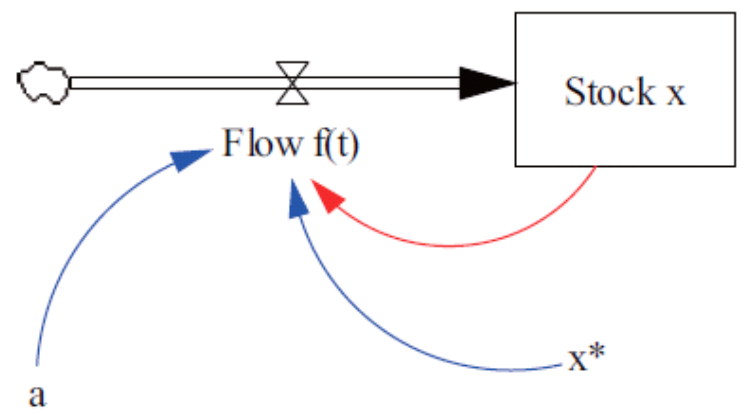

Figure 12: S-Shaped Limited Growth Model (Resource: Yamaguchi, 2013: 41)

(01) Actual Customers $=$ INTEG(sales, 10)

(02) BASE CONTACT RATE $=0.02$

(03) FINAL TIME $=10$

(04) INITIAL TIME $=0$

(05) Potential Customers $=$ INTEG(-sales,

INITIAL TOTAL RELEVANT POPULATION - Actual Customers)

(06) sales $=$ BASE CONTACT RATE $*$ SALES PER CONTACT

* Actual Customers * Potential Customers

(07) SALES PER CONTACT $=0.1$

(08) SAVEPER $=$ TIME STEP

(09) TIME STEP $=0.0625$

(10) INITIAL TOTAL RELEVANT POPULATION $=500$

\section{CURRENT}

INITIAL TOTAL RELEVANT POPULATION

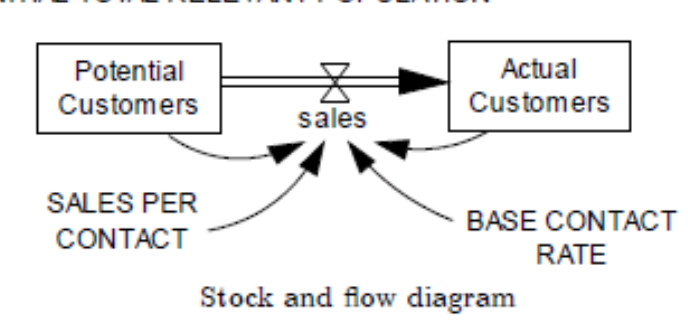

Actual Customers

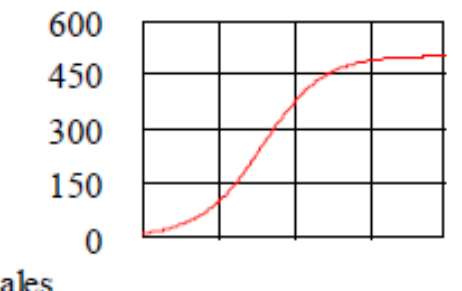

sales

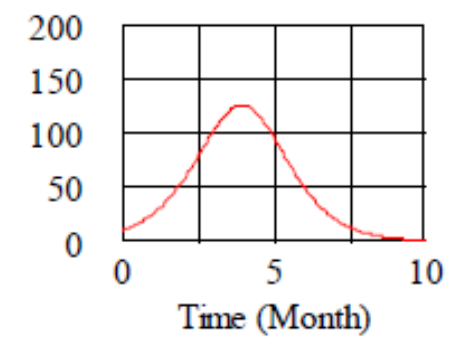

Customer and sales performance

Figure 13: S-Shaped Growth Process (Resource: Kirkwood, 1998: 36) 


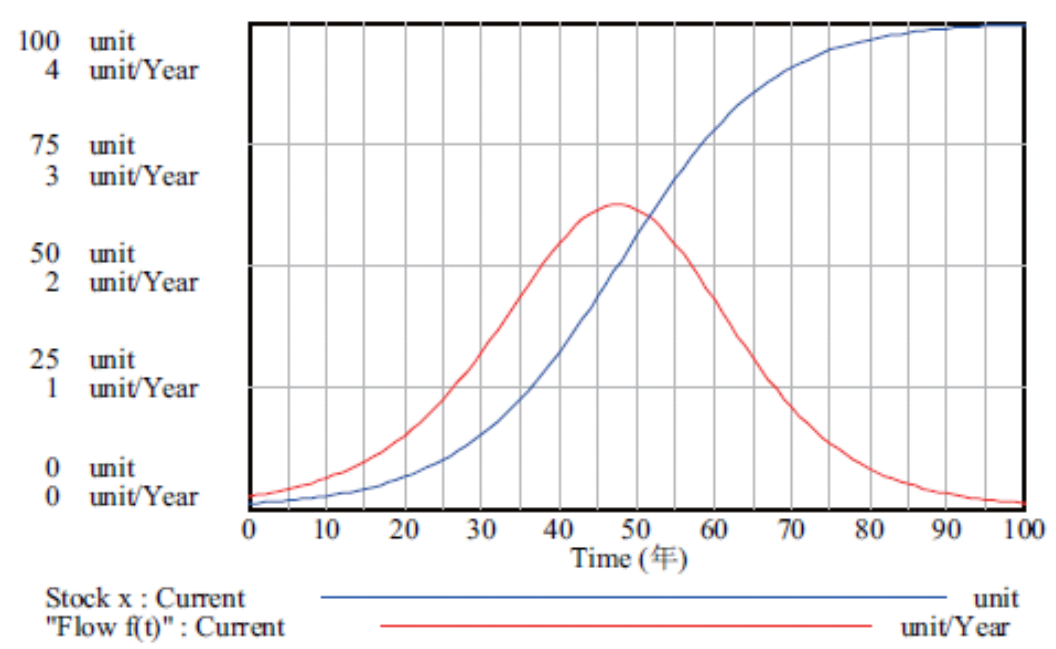

Figure 14: S-Shaped Limited Growth (Resource: Yamaguchi, 2013: 41)

Another way of limiting the growth of $\mathrm{x}(t)$ is to bring $\mathrm{b}(t)$ closer to value $\mathrm{a}$ as $\mathrm{x}$ $(t)$ increases and approaches $x^{*}$. Then, the flow is expressed as follows (Yamaguchi, 2013: 42):

$$
f(x)=(a-b(t)) x(t)
$$

Where $b(t)=a \frac{x(t)}{x^{*}}$

Then, $f(x)=(a-b(t)) x(t)=a\left(\frac{x^{*}-x(t)}{x^{*}}\right) x(t)$.

\subsection{S-Shaped Growth with Overshoot}

The negative feedback in S-shaped growth limits the growth slowly as the growth rate approaches the limit. However, negative feedbacks often contain time delays. The time delay in the negative feedback causes the system to exceed the limit value and exhibit oscillation behavior around the limit value. This structure could be clearly observed in Figure 15 (Sterman, 2000: 121). 


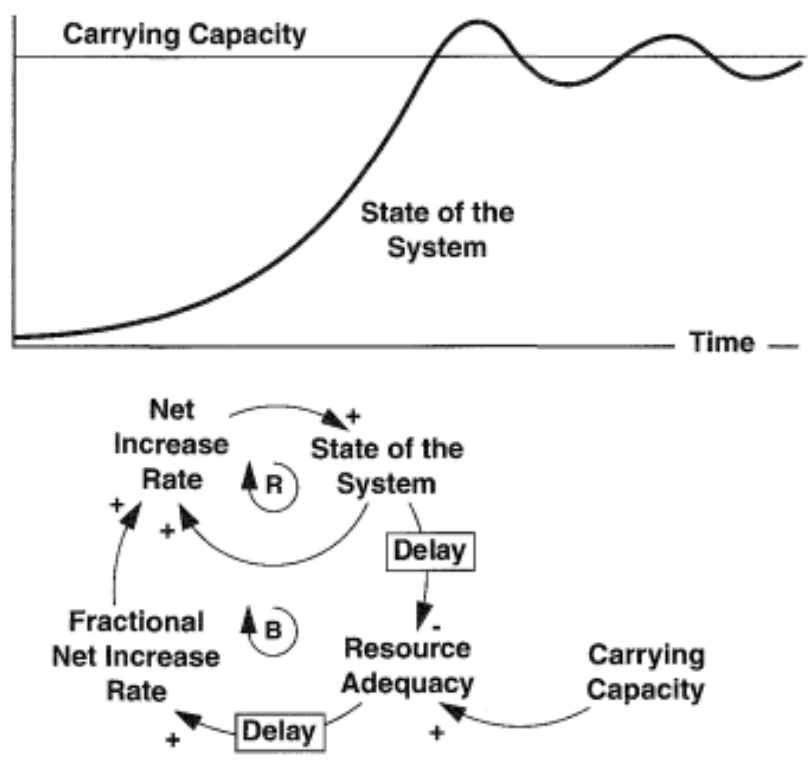

\section{Figure 15: Example of a S-Shaped Growth with Overshoot}

\subsection{Overshoot and Collapse}

A significant assumption in S-shaped growth is that the limit value $\left(x^{*}\right)$ is constant. However, the ability of the environment to support an increasing population depreciates over time, or the population is consumed by itself. The number of deer in a forest could increase so much that it results in hunger and a decrease in the forest population. Figure 29 demonstrates the overshoot and collapse (Sterman, 2000: 124).

The consumption of resources and overshoot created by the population generate a second negative feedback. As the population grows, resources are reduced in two parts. The first is the reduction of possible resources per capita, and the other is the reduction of total resources. In case of S-growth, the resources are initially sufficient enough, the positive feedback loop is dominant and the system grows exponentially. As the growth continues, sufficiency of the resources decreases. Negative feedback grows stronger gradually. At one point, the net rate of increase is reset and the population reaches its maximum. But unlike the S-shaped growth, the system has not reached the equilibrium state. When the population reaches the maximum, the decrease rate of the capacity is increased to a maximum. As the capacity decreases, the capacity per unit population decreases as well and the rate of decrease of the population becomes negative. The system state is reduced and the remaining population continues to consume. Thus, per capita capacity is reduced. If the capacity is not renewed, the system equilibrium means the collapse of the population. 

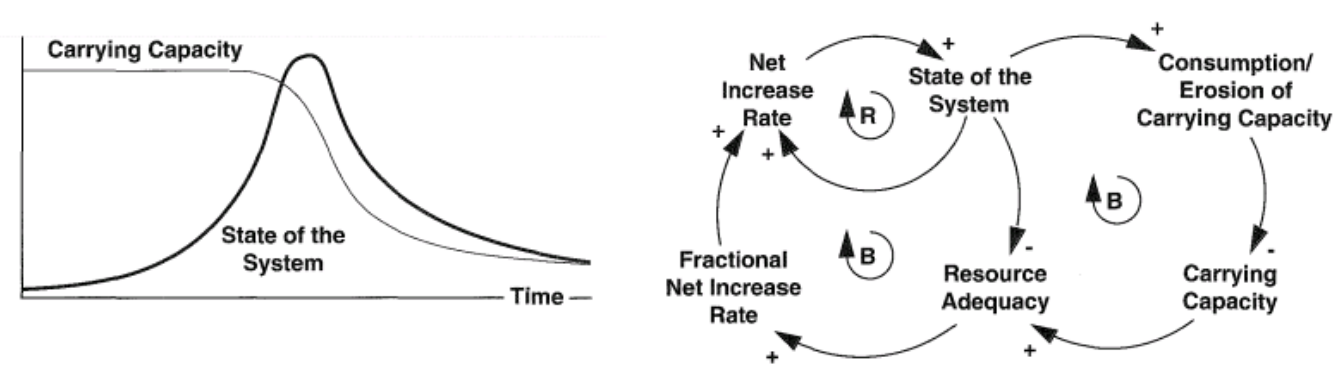

Figure 16: Overshoot and Collapse (Resource: Sterman, 2000: 124)

Overshoot and collapse is observed frequently in complex systems. Initially, the system behavior seems satisfactory. An example is the population increase in Goldfield. Exponential growth is not constant. The increase in stocks is necessary and often leads to the depletion of non-renewable resources (such as gold). Growth in stocks slows down. After a while, diminishing resources cause the growth to cease altogether. Due to lack of resources, stocks start to decrease and collapse rapidly. The exodus of gold miners from Goldfield was a similar event (Breierova, 1997: 6).

\subsection{Other Types Of Behavior}

There are other types of behavior besides growth, goal seeking, oscillation, and the combinations of these. Examples are equilibrium (or stasis), random variation and chaos.

Equilibrium: There are two main reasons for the equilibrium to occur: the first is that changes in the system gradually change the system state and the variations become unnoticable, while the other is due to the fact that the system state becomes almost constant as a result of very strong negative feedbacks.

Random Variation: It is observed that several variables change randomly. The randomness of a system behavior or the random variations in certain variables in the system is not a unique result of the known system dynamics, but a result of other dynamics that we cannot precisely explain and know the reasons of. On the other hand, random external shocks (random external noises) that the system is exposed to could be extremely effective on the system.

Chaos: This behavior is an oscillatory motion, and the reaction of the system is completely unclear. Even though the behavior of a chaotic system are completely deterministic, it is composed of irregular and non-repetitive oscillations (Sterman, 2000: 127-132; Steel et al., 2011: 285).

\section{A Case Study}

In this study a logistic system was modeled using Vensim Package Program. This model includes two stocks and three flows. Firm wants to analyze the values of product stock, order in transit and received order for 100 weeks. In developed model initial value of goal stock level is 12 . 
The weekly product demand is 4 and 10 weeks later it will increase to 8 . We can defined this $\operatorname{DEMAND}=4+\operatorname{STEP}(4,10)$ as variable. And the other equations in developed model are shown as belown.

FINAL TIME $=100$

GOAL STOCK LEVEL $=12$

ORDER IN TRANSIT= INTEG (TRUCK LOADING ORDER-RECEIVED

ORDER,18)

ORDER QUANTITY=IF THEN ELSE(SALES $>=0$, SALES+(GOAL STOCK

LEVEL-PRODUCT STOCK)/2,0)

PRODUCT STOCK = INTEG $($ RECEIVED ORDER-SALES, 12$)$

RECEIVED ORDER=DELAY FIXED( TRUCK LOADING ORDER, 2, 8)

SALES $=$ DEMAND

SAVEPER $=$ TIME STEP

TRUCK LOADING ORDER=ORDER QUANTITY

Developed system dynamic model is shown as Figure 17.

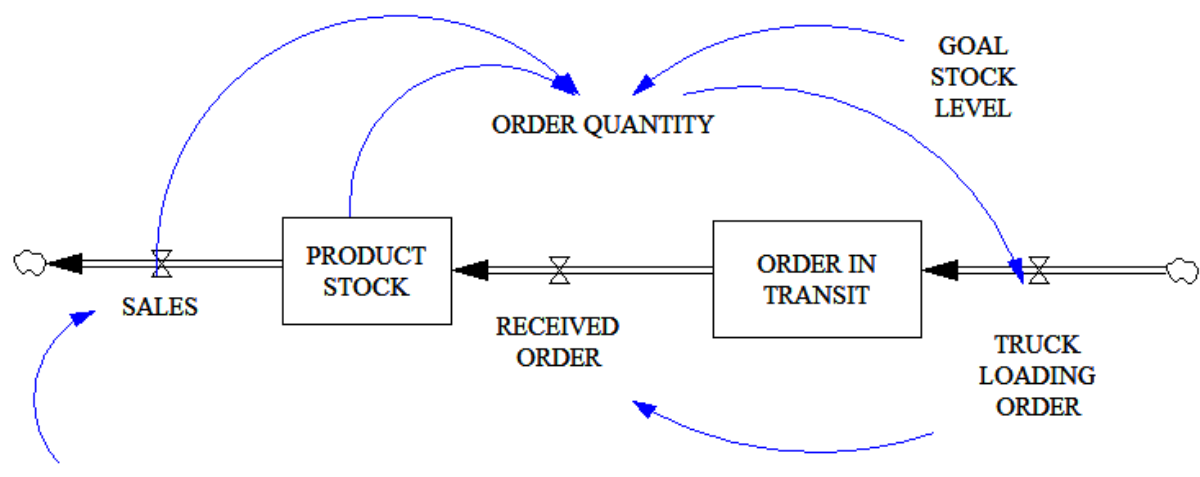

DEMAND

Figure 17: Logistic System Model

When SynthSim modul run in Vensim, Figure 18 is obtained. This screen provides us to see probable effects of parameter changes over analyzed system.

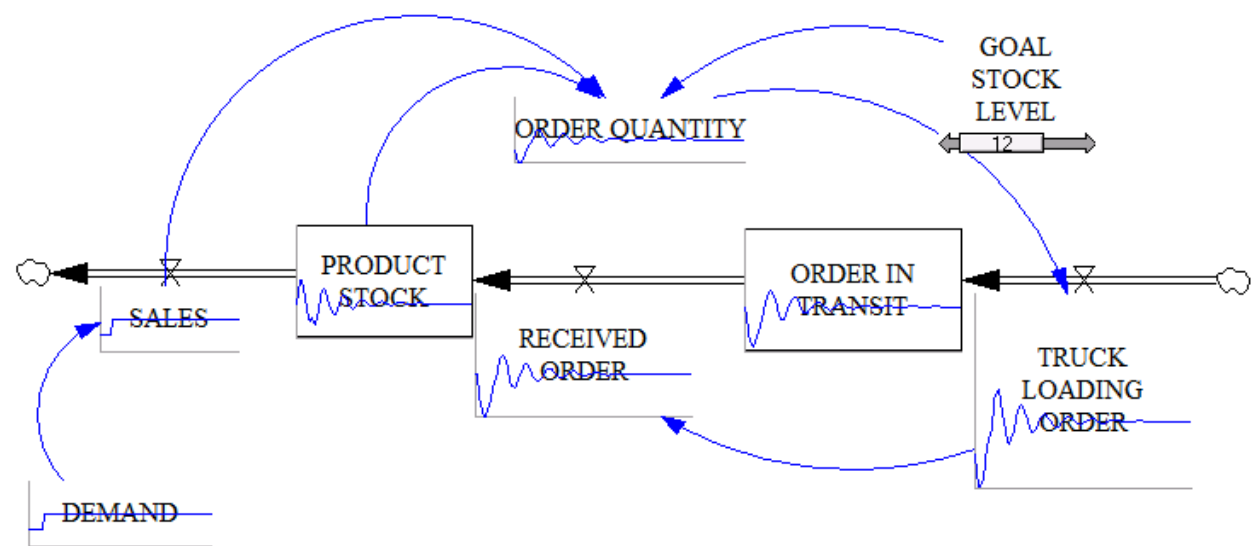

Figure 18: SynthSim modul in Vensim 

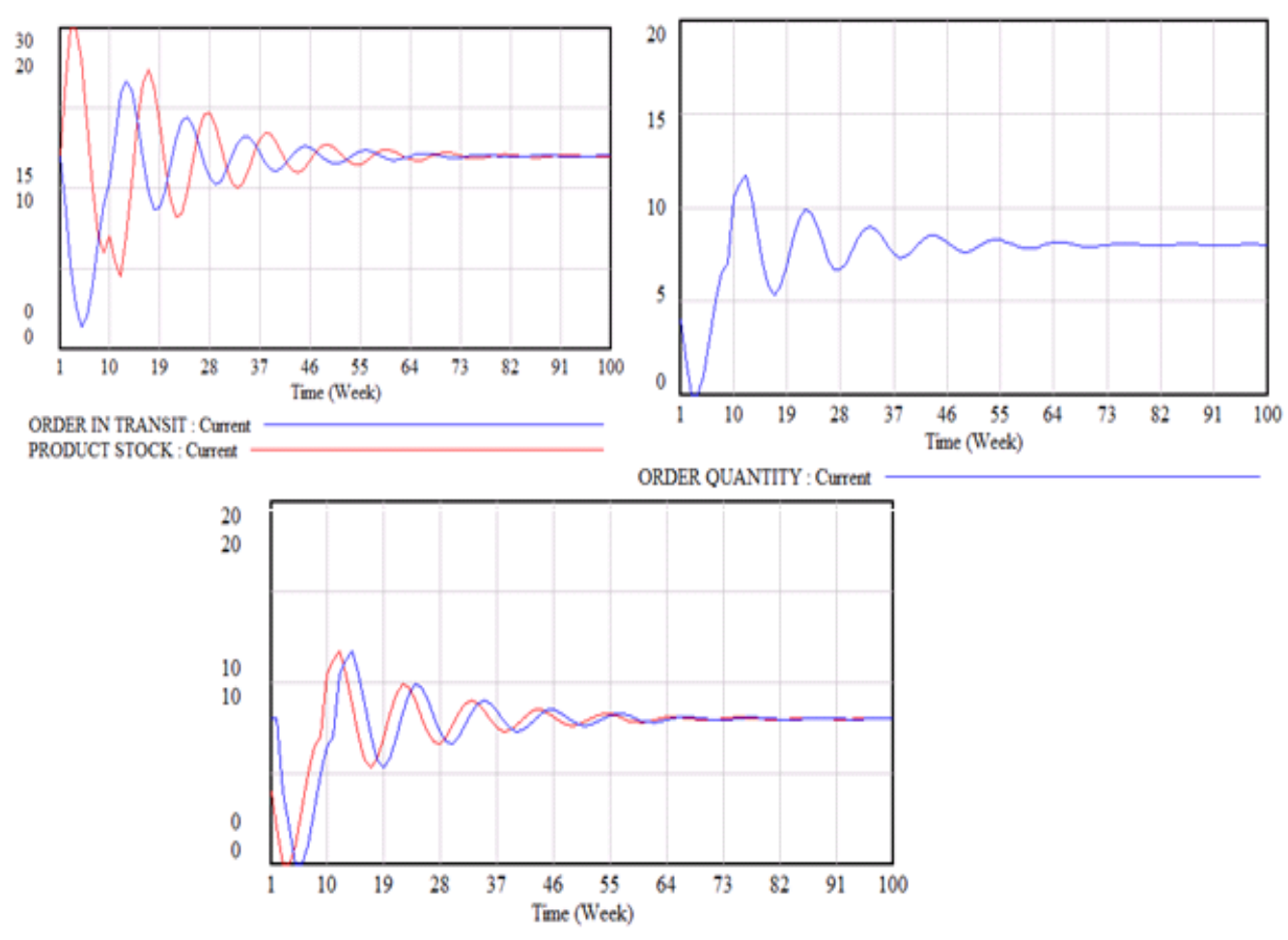

Figure 19: Graph for Results

As it is seen in Figure 19, the system needs to find a common objective or a goal. So this behavior can be describes as Goal Seeking and Oscillation.

\section{Conclusion}

System dynamics deals with how things change over time. Almost all are interested in how the past formed the present moment and how today's actions determine the future. It is a method developed to understand the dynamic behavior of complex systems. The basic principle of system dynamics is that the behavior of the system is rooted in its structure and that the structure of the system (the relations between components) is as significant as the components themselves. Because, the behavior of the whole is often not explained by the singular scrutiny of the components; the behavior of the whole may be quite different from the behavior of the individual components (Öğ̈̈t and Şahit, 2012: 5; Forrester, 1995: 16). 


\section{References}

Abdelbari Hassan, Elsawah Sondoss \& Shafi Kamran (2015). "Model Learning Using Genetic Programming Under Full And Partial System Information Conditions", 33rd International Conference Of The System Dynamics Society, Cambridge, Massachusetts, Usa.

Ayanoğlu M., \& Gökçe M. (2007). “Sistem Düşüncesinden Sistem Dinamiklerine”, Makine Teknolojileri Elektronik Dergisi, (3) 29-41.

Barlas Yaman (2005). Dinamik Sistem Yaklaşımı: Modeller, Kurumsal Öğrenme Ve Sorun Çözme - I. Endüstri Ve Otomasyon Dergisi (94).

Breserova Lucia (1997). Generic Structures: Overshoot And Collapse, Mit System Dynamics İn Education Project

Erkut Haluk (1983). Sistem Dinamiğinin Temelleri, İtü Fen Edebiyat Fakültesi Ofset Atölyesi, İstanbul.

Erkut Haluk (1995). Sistem Yönetimi Yönetim Bilimleri Dizisi: 4, İrfan Yayınları, İstanbul

Ford A. (1999). Modeling The Environment: An Introduction To System Dynamics Modeling Of Environmental Systems, Island Press: Washington, Dc.

Forrester Jay Wright (1962). Industrial Dynamics, Waltham, Ma: Pegasus Communications.

Forrester Jay Wright (1995). Road Map 1: Counterintuitive Behaviour Of Social Systems.Mit System Dynamics In Education Project.

Forrester Jay Wright (2007). "System Dynamics: A Personal View Of The First Fifty Years", System Dynamics Review Vol 23, 345-358.

Glick Marc, (2001). Generic Structures: S-Shaped Growth I, Mit System Dynamics İn Education Project.

Lane David J. \&Sterman John D. (2011). Profiles İn Operations Research: Jay Wright Forrester, Chapter 20 İn Profiles İn Operations Research: Pioners And Innovators. S. Gass And A. Assad, New York, Springer: 363-386.

Kirkwood Craig W. (1998). System Dynamics Methods: A Quick Introduction, College Of Business Arizona State University.

Maani Kambiz E. \& Cavana Robert Y. (2007). Systems Thinking And Modelling Understanding Change And Complexity, Pearson Education, New Zealand.

Öğüt Kaan \& Şahin Serçin (2012). “ Türkiye'de Finansal İstikrar Sorununa Sistem Dinamiği Yaklaşımı”, Türkiye Ekonomi Kurumu.

Ramage Magnus \& Ship Karen (2009). Sytem Thinkers, The Open University Walton Hall, Milton Keynes United Kingdom, Springer London.

Morecroft John (2015). Strategic Modelling And Business Dynamics: A Feedback Systems Approach, John Wiley \& Sons, Chichester, England.

Senge Peter (1990). The Fifth Discipline: The Art And Practice Of The Learning Organization. Random House, London. 
Senge, Peter, Kleıner, A., Roberts, C., Ross, R. \& Smith, B. (1994). The Fifth Discipline Fieldbook, Century, London.

Sezen H. Kemal., (2007). Yöneylem Araştırması, Ekin Yayınevi, Bursa.

Sezen H. Kemal., Günal Murat. (2009). Yöneylem Araştırmasında Benzetim, Ekin Yayınevi, Bursa.

Sterman, John.D. (2000). Business Dynamics Systems Thinking And Modelling In A Complex World, Mcgraw-Hill, New York. Http://Www.Simposio.Palmira.Unal.Edu.Co/Documentos/Sterman_Business_Dy namics.Pdf

Yamaguchi Kaoru (2013). Money And Macroeconomic Dynamics- Accounting System Dynamics Approach, Awaji Island, Japan: Japan Future Research Center. 